\title{
ТАКСИС И КВАНТИТАТИВНОСТЬ В КОНТЕКСТЕ ИНТЕГРАТИВНОГО ВЗАИМОДЕЙСТВИЯ
}

\section{TAXIS AND QUANTITATIVITY IN THE CONTEXT OF INTEGRATIVE INTERACTION}

\section{Arkhipova}

Summary: The article discusses the functional-semantic categories of taxis and quantitativity in the context of the intercategory integrative interaction. The paper describes various quantitatively determined elements of the syntagmatic context: deverbatives of genetic and wordformation multiplicity; iterative verbs; iterative quantifiers (adverbials, attributes), temporal, taxis and aspectual quantifiers, as well as the plurality of subject and object actants of verbal action. Within the framework of the polycategorical complex, statements with prepositional deverbatives actualize quantiative-deterministic taxis categorical situations of simultaneity and asynchronicity (iterative, multiplicative, distributive, etc.). Aspectual, temporal, and taxis quantifiers participate in the linguistic representation of aspectual-taxis values of partial simultaneity and asynchronicity (strict, non-strict), performing the functions of temporal delimiters and taxis explicators of asynchronicity.

Keywords: functional-semantic category, functional-semantic field, integrative interaction, taxis, quantiativity, quantifiers, polycategorical complex, quantitative-deterministic taxi categorical situations.

\author{
Архипова Ирина Викторовна \\ к.филол.н., профессор, Новосибирский государственный \\ педагогический университет \\ irarch@yandex.ru
}

Аннотация: В статье рассматриваются функционально-семантические категории таксиса и квантитативности в контексте межкатегориального интегративного взаимодействия, а также различные квантитативно-детерминированные элементы синтагматического контекста: девербативы генетической и словообразовательной кратности; итеративные глаголы; итеративные квантификаторы (адвербиалы, атрибуты), темпоральные, таксисные и аспектуальные квантификаторы, а также множественность субъектных и объектных актантов глагольного действия. В рамках поликатегориального комплекса в высказываниях с предложными девербативами актуализируются квантитативно-детерминированные таксисные категориальные ситуации одновременности и разновременности (итеративной, мультипликативной, дистрибутивной и др.). Аспектуальные, темпоральные и таксисные квантификаторы участвуют в языковой репрезентации аспектуально-таксисных значений частичной одновременности и разновременности (строгой, нестрогой), выполняя функции темпоральных делимитаторов и таксисных экспликаторов разновременности.

Ключевые слова: функционально-семантическая категория, функциональносемантическое поле, интегративное взаимодействие, таксис, квантитативность, квантификаторы, поликатегориальный комплекс, квантитативно-детерминированные таксисные категориальные ситуации.

$[1$, c. $34-35 ; 2$, с. $149-158 ; 3$, с. $135-138 ; 4$, c. 196-198; 7, c. 149-153; 8, с. 74-80; 9, с. 131-136; 12, с. 234-241] и актуализирующееся в таксисных категориальных ситуациях одновременности/разновременности, представляющих собой «типовые содержательные структуры, базирующиеся на определенной семантической категории и соответствующем ФСП» [13, с. 39-40]. Квантитативность (количественность) рассматривается с позиций функциональной грамматики как семантическая категория, «представляющая собой языковую интерпретацию мыслительной категории количества» и полицентрическое функционально-семантическое поле (ФСП), которое конституируется разноуровневыми языковыми единицами, взаимодействующими на основе квантитативных функций [11, с.161].

Категория квантитативности (количественности, количества) неоднократно освещалась в исследованиях В.С. Храковского, Ю.И. Бажановой, А.В. Степановой, Т.М. Тагоевой, Л.Н. Моисеенко, Н.С. Чиркинян, Ю. Цзян, Ц. Цзя и др., проводимых на материале разноструктурных языков (русского, английского, немецкого, китайского, чувашского, таджикского, армянского и др.) [10; 16; 17; 18; 
$19 ; 20 ; 21 ; 22 ; 23]$. Современные исследователи отмечают полицентричность данной семантической категории, ее многоаспектность и неоднородность (диффузность) в сферах именной и глагольной квантитативности. Они выделяют различные количественные значения (единичность, множество (неопределенное, определенное, дискретное, дробное, собирательное), дискретное количество, множественность (кратность/итеративность), длительность (ограниченная/неограниченная; точная/ приблизительная), интенсивность и др.) [10, с. 12-13; 16, с. 6-15; 22, с. 6-7].

Полицентрический характер ФСП квантитативности (количественности, количества) и его диффузная структура позволяют дифференцировать семантику определенного и неопределенного количества и проводить дальнейшую субкатегоризацию данной категории. Субполе определенного количества состоит из микрополей нумеральности, единичности и нулевого количества, а субполе неопределенного количества конституируется микрополями приблизительного, неопределенно большого и неопределенно малого количества [17, с. 5]. В качестве ядра (центра) данного ФСП определяется грамматическая категория числа в виде бинарной оппозиции «единичность - множественность», а к периферийным языковым средствам относятся разноуровневые лексические и лексико-грамматические средства: количественные числительные, количественные местоимения, наречия, глаголы, квантитативные имена существительные, квантитативно-именные сочетания, адъективные квантификаторы на основе параметрических прилагательных, адвербиальные квантификаторы и др.

Поликатегориальный субкомплекс таксиса и квантитативности характеризуется интегративным взаимодействием в сфере глагольной (предикатной) и именной множественности (количественности, квантитативности) в высказываниях с предложными девербативами. Кроме того, в фокусе интегративного взаимодействия данных функционально-семантических категорий находятся адвербиальные единицы с различными квантитативными характеристиками: темпоральные, аспектуальные и таксисные квантификаторы. В сфере именной множественности речь идет о девербативах с признаками генетической и словообразовательной кратности (das Kreischen, das Schluchzen, das Schnarchen, das Schnattern, das Scharren, das Rascheln, das Rauschen, das Sausen, das Schwirren, das Schulterzucken, die Besichtigungen, die Beobachtungen, die Unterhaltungen, die Befragungen, die Unterredungen, die Wanderungen, die Begegnungen, die Angriffe, die Besuche) [5, c. 26-28; 6, с. 564-565]. Последние употребляются в форме множественного числа и маркируют определенную (точную) (nach vier Begegnungen, nach zwei Untersuchungen, nach drei Besichtigungen, nach zwei Treffen) или неопределенную квантификацию процессов, действий или событий, выражаемых деверба- тивными существительными (während der Beobachtungen, nach weiteren Begegnungen и др.). Например:

Mit dem charakteristischen Knistern erhebt sich Schirm um Schirm in die heisse Nachmittagsluft. (www.zuonline. ch, gecrawlt am 26.03.2018).

Ein Rebhuhn wird aufgescheucht, flüchtet mit blechernem Krächzen. (www.fnp.de, gecrawlt am 28.03.2018).

Nach vier Begegnungen sind die Geheimnisse der Teams entschlüsselt, die besten Spieler und ihre Vorlieben durchleuchtet. (www.merkur.de, gecrawlt am 26.03.2018).

Nach zwei Untersuchungen schickte er den Jogger ins Spital Bülach. (www.beobachter.ch, gecrawlt am 25.03.2018)

Forscher fanden während der Beobachtungen eine verstreute Gruppe junger Sterne, die erst im Entstehen sind. (www.gmuender-tagespost.de, gecrawlt am 27.03.2018).

Nach weiteren Begegnungen mit der jungen Frau lässt er sich sogar zu einem Tanzkurs überreden. (www.azonline.de, gecrawlt am 28.03.2018).

Девербативы генетической и словообразовательной кратности, а также глаголы-мультипликативы и глаголы-итеративы (flattern, wippen, ächzen, flüstern, zucken, seufzen, schlucken, klopfen, https://corpora.uni-leipzig. de/de/res?corpusld=deu_newscrawl-public_2018\&word =brummenschnalzen, lallen, zischen, krächzen, rutschen, schnarren, streichen, schnattern, summen, sausen, brummen, rasseln, stammeln, lächeln, streicheln, gackern, rattern) актуализируют итеративно-таксисные и мультипликативнотаксисные значения одновременности/ разновременности [5, с. 26-28; 6, с. 564-565]. Например:

Als Garbani eine Klappe öffnet, sausen sie mit lautem Zischen und in eine große Auffangschale aus Metall. (www. paz-online.de, gecrawlt am 29.03.2018).

Finger weg von langen Ketten: Sie baumeln von der Brust ins Leere und wippen beim Gehen auf und ab. (www. bild.de, gecrawlt am 28.03.2018).

Интегративный сегмент взаимодействующих ФСП таксиса и квантитативности включает следующие квантитативно-детерминированные элементы синтагматического контекста в высказываниях с предложными девербативами:

1. девербативы-итеративы и девербативы-мультипликативы на -en, -ung, -e, -t, -ø с семантикой генетической или словообразовательной кратности;

2. глаголы итеративной семантики (собственно итеративные, диминутивно-итеративные, интенсивно-итеративные, мультипликативные, дистрибутивные);

3. темпоральные и таксисные квантификаторы (моно-, би- и поликомпонентные) (jetzt, 
heute, morgen, bald, damals, gestern, gleich, sofort, unmittelbar, direkt, dann, im vorigen Jahr, im Januar, in den vergangenen Wochen, in den letzten Tagen, am Tag, eine Stunde zuvor, in nächster Woche, in den nächsten Tagen): Nach dem ersten Erscheinen im Januar war der Ratgeber schnell vergriffen. (www. stadtzeitung.luebeck.de, gecrawlt am 26.03.2018); Am Tag vor der Abreise annulliert er seine Buchung. (www.beobachter.ch, gecrawlt am 28.03.2018); In den letzten Tagen vor Erscheinen der Seiten bekommen sie dann den Feinschliff. (www.sueddeutsche.de, gecrawlt am 26.03.2018); In den nächsten Tagen bis zur Abreise wird die stürmische Melodie zum Ohrwurm und Hit der Reise. (www.donaukurier.de, gecrawlt am 25.03.2018); Beim Beobachten ihrer Arbeit waren De Lucchi damals die Seilzüge der Angeln aufgefallen. (www.welt.de, gecrawlt am 26.03.2018); Sein Leibarzt äußerte sich direkt nach der Untersuchung zum Zustand des Präsidenten. (www.express.de, gecrawlt am 28.03.2018);

4. аспектуальные квантификаторы с семантикой длительности (ограниченной/неограниченной, точной/приблизительной), фазовости и др. (viel, kurz, lang, lange, fünfminütig, eine Stunde zuvor, zehn Stunden, anderthalb Stunden, ein paar Wochen, ein paar Tage, rund ein Jahrzehnt, kurze Zeit, zwei Tage, plötzlich, schließlich, endgültig, bereits): Bereits eine Stunde zuvor, mit dem Dunkelwerden, brannten auf der 4. Dorfweihnacht wieder die Schwedenfeuer. (www.nnn.de, gecrawlt am 28.03.2018); Erst Wochen nach zwei kurz aufeinander erfolgten Treffen mit Franz, lange nach Erscheinen des Artikels, kam auf einmal ein merkwürdiges Misstrauen auf. (www.az.com.na, gecrawlt am 28.03.2018);

4a. аспектуальные адвербиалы (в составе предложно-девербативных конструкций и в общей структуре комплексного высказывания): Nach zehn Stunden Nähen in einer Nacht, Anbringen von Drückknöpfen und Klinikum-Logo war der Prototyp fertig. (www.nordbayerischer-kurier.de, gecrawlt am 26.03.2018); Rund ein Jahrzehnt nach dem Erscheinen bezahlt der jüdische Autor Arthur Schnitzler für diese Position. (www.cosmopolis.ch, gecrawlt am 25.03.2018); Das Thema war für mich kurze Zeit nach dem Erscheinen des Aufgebots bereits abgehakt. (www.basellandschaftlichezeitung.ch,gecrawlt am 28.03.2018); Beim Bohren springt plötzlich die Sicherung aus. (www.radiohamburg.de, gecrawlt am 28.03.2018); Nach Klingeln und Klopfen wurde schließlich geöffnet, und die Ordnungshüter drangen in die Wohnung vor. (www.mainpost.de, gecrawlt am 26.03.2018);

46. аспектуальные (дуративные (имперфективные), недуративные (перфективные) атрибуты) (lang, wochenlang, monatelang, mehrmonatig, halbstündig, fünfminütig, kurz, kürzer, länger): Nach fünfminütigem Ziehen lassen in kochendem Wasser wird die Tee-Flüssigkeit durch die wie ein Filter wirkenden gezackten Tassenränderin bereit stehende Teeschälchen umgegossen. (www.epochtimes.de, gecrawlt am 28.03.2018); Mark Zuckerberg hat sich nach langem Schweigen nun endlich zu den Vorwürfen wegen Cambridge Analytica geäußert. (www.faz.net, gecrawlt am 25.03.2018); Nach kurzem Abtasten kam die Heimmannschaft zur ersten Möglichkeit. (www. muensterschezeitung.de, gecrawlt am 27.03.2018); Deshalb wurde das Rennen nach einer halbstündigen Verschiebung aus Sicherheitsgründen abgesagt (www.bvz. at, gecrawlt am 27.03.2018);

5. итеративные квантификаторы: адвербиалы цикличности, кратности, интервала, счетного комплекса, определенной/неопределенной частотности, узуальности и др. (stets, morgens, abends, nachts, sonnabends, freitags, sonntags, beständig, mehrmalig, mehrfach, mehrmals, häufig, zweimal, dreimal, gewöhnlich, manchmal, oft, meist, meistens, jedesmal, oftmals, nochmals, immer, immerfort) [5, c. $26-28 ; 6$, c. $564-565 ; 14$, c. 9-10; 15 , c. $174 ; 19$, c. 19-20]: Bei so vielen Terminen habe sie immer im Gehen etwas gegessen. (www.stern.de, gecrawlt am 27.03.2018); Morgens nach dem Aufstehen setzen wir uns an den Frühstückstisch. (www.focus.de, gecrawlt am 25.03.2018); Das mache ich immer als Erstes nach dem Aufstehen und als Allerletztes vor dem Schlafengehen. (www.giessener-allgemeine.de, gecrawlt am 29.03.2018);

6. итеративные квантификаторы: итеративные атрибуты (jeder, mehrmalig, mehrfach, meist и др.): Lüften, lüften, lüften ist speziell angesagt, denn auch beim Schlafen gibt jeder Mensch Wasserdampf ab. (www. pattayablatt.com, gecrawlt am 26.03.2018); Nach mehrmaligem Reklamieren an diversen Stellen, wurde mein Velo an eine zentral gelegene Polizeistelle in der Stadt gebracht, wo ich es dann kostenlos abholen konnte.(www.tagblattzuerich.ch, gecrawlt am 25.03.2018); Durch mehrfaches, starkes Klopfen der Feuerwehrbeamten öffnete eine junge Frau. (www. wochenanzeiger.de, gecrawlt am 25.03.2018);

7. множественность субъектных/объектных актантов действий комплексной ситуации высказываний, характеризующихся квантитативно-детерминированной аспектуально-таксисной семантикой: Nach Rückkehr der Radler werden im Stadion Getränke und Essen angeboten, zudem gibt es Aktionen und Infostände. (www.mittelhessen.de, gecrawlt am 27.03.2018); Nach dem Luftangriff auf ein Spital in der syrischen Stadt Aleppo weisen alle Kriegsparteien nach wie vor jegliche Verantwortung zurück. (www. srf.ch, gecrawlt am 26.03.2018); Bis zum Eintreffen der Gäste haben die Helferinnen die Tische gedeckt und mit frischen Blumen dekoriert. (www.wn.de, gecrawlt am 28. 03. 2018). 
Квантитативно-таксисные высказывания с предложными девербативами могут характеризоваться синкретизмом взаимодействующих квантитативных компонентов, например, итеративного атрибута meist или итеративного-темпорального квантификатора die meiste Zeit des Tages и множественности субъектных актантов глагольного действия. Например:

Schon beim Betreten sind die meisten Besucher von der Helligkeit und Großzügigkeit angenehm überrascht. (www. wochenanzeiger.de, gecrawlt am 25. 03. 2018).

Die meiste Zeit des Tages verbringen viele Menschen im Sitzen: Da sind Rückenschmerzen oftmals vorprogrammiert. (www.sat1.de, gecrawlt am 28.03.2018).

Квантитативно-детерминированный характер высказываний с семантикой субъектной и объектной множественности определяет актуализацию аспектуально-таксисных значений дистрибутивной одновременности и разновременности. Ср.:

Beim Öffnen der Balkontür atmeten jedoch zwei Kinder im Alter von drei Jahren sowie elf Monaten Rauch ein und wurden leicht verletzt. (www.nnp.de, gecrawlt am 26.03.2018).

Direkt nach dem Öffnen der Hallen am Mittwochmorgen strömten bereits zahlreiche Fachbesucher durch die Tore. (www.hersfelder-zeitung.de, gecrawlt am 26.03.2018).

Ihre Erkenntnisse sammelt sie beim Tauchen mit wild lebenden Delfinen. (www.nnn.de, gecrawlt am 25.03.2018).

Квантитативно-детерминированные высказывания с аспектуально-таксисной семантикой одновременности/разновременности характеризуются синкретизмом генетической/словообразовательной итеративности девербативов (мультипликативной, итеративной, дистрибутивной), вербальной итеративности и квантитативно-адвербиальной или квантитативно-атрибутивной итеративности. Соответственно, в рамках интегративного поликатегориального субкомплекса таксиса и квантитативности (итеративности) выделяются такие квантитативно-детерминированные или итеративно-таксисные категориальные ситуации как: девербативно-итеративные (при наличии девербативов с интегральным признаком «генетическая/словообразовательная кратность»), вербально-итеративные (при наличии мультипликативных, собственно итеративных, диминутивно-итеративных, интенсивно-итеративных, дистрибутивных глаголов) и адвербиально-итеративные или атрибутивно-итеративные (при наличии различных итеративных квантификаторов) [6, с. 564].

В высказываниях с таксисообразующими предлогами vor, nach, bis, seit при наличии темпоральных, аспектуальных и таксисных квантификаторов репрезентируются аспектуально-таксисные категориальные ситуации следования и предшествования: строгого (дистантного) и нестрогого (контактного). Квантитативные атрибуты и адвербиалы (kurz, lang, tagelang, stundenlang, wochenlang, monatelang, lange, gleich, unmittelbar, direkt, endlich, bald, viel, zwei/drei Wochen, eine Stunde, ein paar Stunden, (knapp) ein Jahr, zwei Jahre, drei Jahre, hundertjährig, zweihundertjährig и др.) конкретизируют темпоральное (временное) расположение обозначаемых в высказываниях действий (процессов, событий), маркируя некоторый временной промежуток, имеющий место между их «индивидуальными внутренними временами» (т. е. временами их совершения или осуществления). При этом они выполняют две функции: функцию темпоральной делимитации (т.е. отграничения следующих друг за другом или предшествующих друг другу действий, процессов, событий) и функцию лексическо-семантических экспликаторов разновременности. Например:

Nach monatelanger Verzögerung hat die afghanische Regierung den Weg für einen internationalen Militäreinsatz über das Jahresende hinaus freigemacht. (www.taunuszeitung.de, gecrawlt am 26.03.2018).

Unmittelbar nach der Kündigung Schmids hatte ich mit ihnen eine Sitzung. (bazonline.ch, gecrawlt am 26.03.2018).

Kurz nach seiner Anreise traf er sich bereits mit dem tschechischen Außenminister Lubomír Zaorálek zu einem informellen Abendessen. (www.radio. Cz, gecrawlt am 25.03.2018).

Kurz vor der Kündigung hatten diese noch eine saftige Lohnerhöhung bekommen. (www.srf.ch, gecrawlt am 27.03.2018).

В высказываниях с предлогом mit в темпоральном значении актуализируются аспектуально-таксисные категориальные ситуации частичной одновременности. Квантитавно-детерминированная таксисная семантика таких высказываний, характеризуется, как правило, синкретичным объединением значения одновременности и ингрессивности (начала действия). Сопутствующее действие девербатива является «отправной точкой» основного действия фазового глагола (его ингрессивной или эгрессивной «точкой»): beginnen, anfangen, enden, beenden и др. Ср.:

Mit seinem Eintreffen beginnt die Luft buchstäblich zu vibrieren. (www.tt. com, gecrawlt am 25.03.2018).

Nach Erscheinen des Artikels hatte das SEM damit begonnen, die Vorwürfe zu prüfen. (www.blickamabend.ch, gecrawlt am 27.03.2018).

Mit dieser Begegnung beendet Zeman die Reihe von Gesprächen, die er mit den Spitzenvertretern der Regierungs- und Oppositionsparteien geführt hat. (www. radio.cz, gecrawlt am 25.03.2018).

Кроме того, в некоторых высказываниях с квантитативно-детерминированной аспектуально-таксисной семантикой наблюдается полисинкретизм таксисного значения частичной одновременности, аспектуальной семантики ингрессивности (предлог mit), семантики темпоральной квантификации (in den vergangenen Wochen, just an dem Tag) и обстоятельственного значения образа действия, в результате чего актуали- 
зируются аспектуально-таксисные категориальные ситуации секундарного (обстоятельственного) таксиса, в частности, модально-аспектуально-таксисные ситуации: Mit ein paar Tagen Verzögerung schwappte die Kältewelle in den vergangenen Wochen von Mitteleuropa auch nach Spanien. (www.mallorcazeitung.es, gecrawlt am 26. 03. 2018); Mit mehrmonatiger Verspätung bereist er nun sein Heimatland just an dem Tag, an dem der Koalitionsvertrag unterzeichnet wird. (www.aachenerzeitung.de, gecrawlt am 25.03.2018).

Итак, в контексте интегративного взаимодействия ФСК таксиса и квантитативности (количественности) наибольшей прототипичностью характеризуются такие квантитативно-детерминированные элементы синтагматического контекста высказываний с предложными девербативами, как: девербативы генетической и словообразовательной кратности; итеративные глаголы; итеративные квантификаторы (адвербиалы, атрибуты), темпоральные/таксисные/ аспектуальные квантификаторы, а также множественность субъектных и объектных актантов глагольного действия. В высказываниях с предложными девербативами актуализируются различные квантитативно-детерминированные аспектуально-таксисные категориальные ситуации одновременности и разновременности (итеративной, мультипликативной, дистрибутивной и др.), репрезентирующие квантитативно-темпорально-аспектуально-таксисный семантический субкомплекс.

\section{ЛИТЕРАТУРА}

1. Архипова И.В. Высказывание с предложными девербативами в современном немецком языке: монография. Новосибирск: НГПУ, 2012.148 с.

2. Архипова И.В. Кратный таксис в современном немецком языке // Вестник Новосибирского государственного педагогического университета. 2013 . № 6 (16). С. 149-159.

3. Архипова И.В. Предложный девербатив как конституент зависимого таксиса современного немецкого языка // Вестник Новосибирского государственного педагогического университета. 2016. № 4. С. 135-142.

4. Архипова И.В. Категория таксиса в лингвистике (на материале немецких высказываний с предложными девербативами) // Вестник Новосибирского государственного педагогического университета. 2017. № 4. С. 196-205.

5. Архипова И.В. Итеративные девербативы в немецком языке // Актуальные проблемы филологии и методики преподавания иностранных языков. 2017. T. 11. C. 26-28.

6. Архипова И.В. Функционирование девербативов в итеративно-таксисной категориальной ситуации// Мир науки, культуры, образования. 2019. № 6 (79). C. 564-565.

7. Архипова И.В. Синкретизм в сфере актуализации таксисных значений одновременности // Современная наука: Актуальные проблемы теории и практики. Серия: Гуманитарные науки. 2019. № 12. С. 149-154.

8. Архипова И.В. Функциональный потенциал девербативов и его реализация в контексте// Евразийский гуманитарный журнал. 2020. № 1. С. $74-87$.

9. Архипова И.В. Модель функционально-семантического поля таксиса // Современная наука: актуальные проблемы теории и практики. Серия: Гуманитарные науки. 2020. № 1. С. 131-137.

10. Бажанова Ю.И. Репрезентация категории количества в современном немецком языке: Автореф. дис. ... канд. филол. наук. М., 2004. 26 с.

11. Бондарко А.В. Количественность. Вступительные замечания // Теория функциональной грамматики: Качественность. Количественность. СПб.: Наука, 1996. C. 161-162.

12. Бондарко А.В. Общая характеристика семантики и структуры поля таксиса // Теория функциональной грамматики: Введение, аспектуальность, временная локализованность, таксис. Изд.6-е. М.: Книжный дом «Либроком», 2011. С. 234-242.

13. Бондарко А.В. Категоризация в системе грамматики. М.: Языки славянских культур, 2011. 488 с.

14. Комиссарова Е.С. Итеративные адвербиальные единицы в функционально-семантическом аспекте: Автореф. дис. ... канд. филол. наук. Пермь, 2014. 24 с.

15. Кибардина С.М. Выражение множественности действий в немецком языке // Типология итеративных конструкций / Отв. ред. В. С. Храковский. Л.: Наука, 1989. С. 170-179.

16. Моисеенко Л.Н. Количественные представления в сфере глагольного действия (на материале современного немецкого языка): Автореф. дис. ... канд. филол. наук. Омск, 2005. 24 с.

17. Степанова А.В. Функционально-семантическое поле количественности в разноструктурных языках (на материале английского, русского и чувашского языко): Автореф. дис. ... канд. филол. наук. Чебоксары, 2007. 24 с.

18. Тагоева Т.М. Функционально-семантическое поле количественности в английском и таджикском языках: Автореф. дис. ... канд. филол. наук. Душанбе, 2006. 24 C.

19. Храковский В.С. Семантические типы множества ситуаций и их естественная классификация // Типология итеративных конструкций / Отв. Ред. В.С. Храковский. Л.: Наука, 1989. С. 5-54.

20. Храковский В.С. Кратность // Теория функциональной грамматики: Введение, аспектуальность, временная локализованность, таксис. Изд.6-е. М.: Книжный дом «Либроком», 2011. С. 124-152.

21. Цзя Цянь. Семантика квантитативности в именных группах китайского и русского языков: Автореф. дис. ... канд. филол. наук. М., 2017. 19 с. 
22. Цзян Юнминь. Средства выражения именной количественности в современном русском языке: Автореф. дис. ... канд. филол. наук. М., 2004. 36 с.

23. Чиркинян Н.С. Поле количественности на материале русского и армянского языков: Автореф. дис. ... канд. филол. наук. Ереван, 1985. 28 с.

(с) Архипова Ирина Викторовна (irarch@уandex.ru).

Журнал «Современная наука: актуальные проблемы теории и практики»

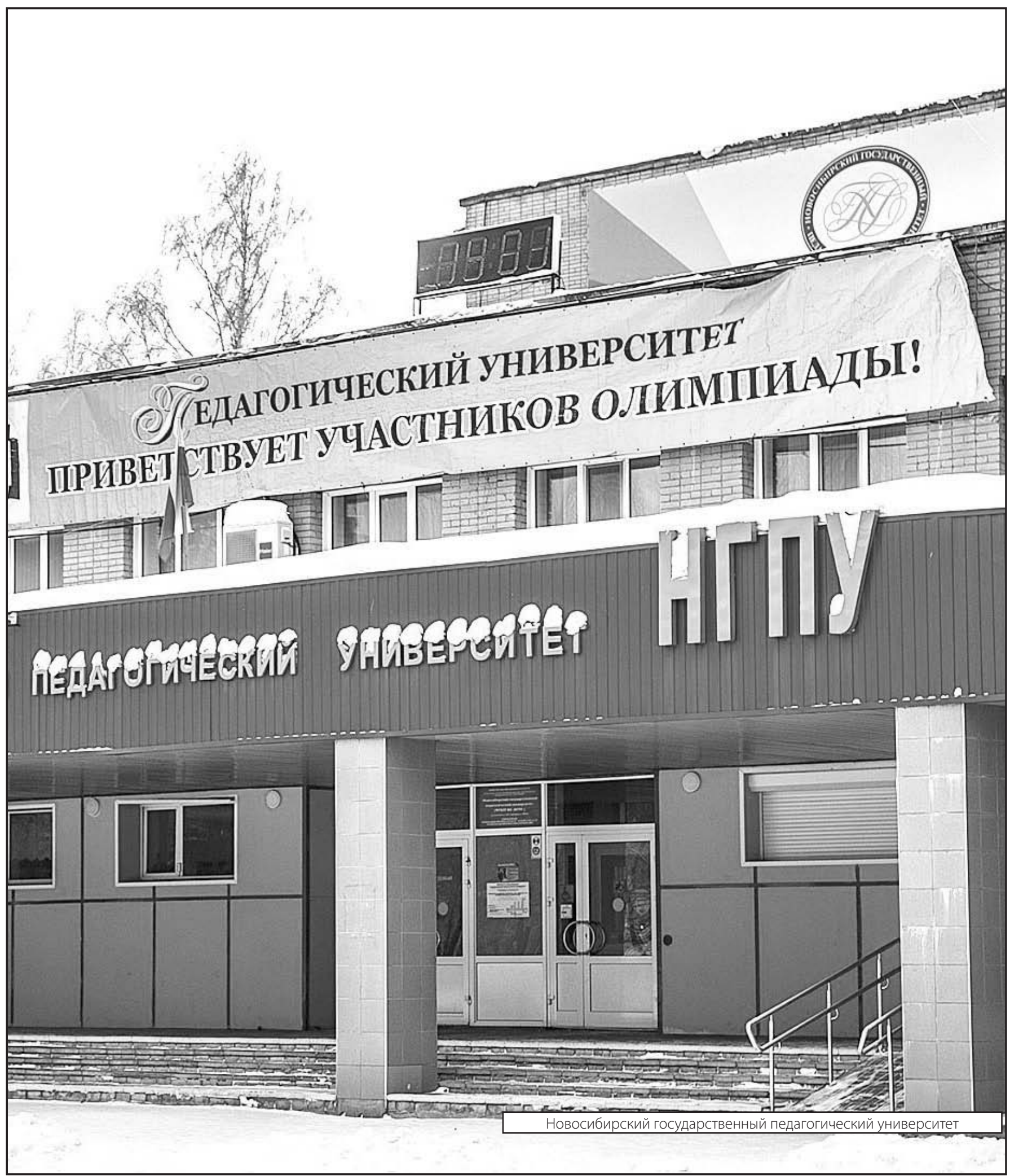

